\title{
Article \\ Effect of Cooking Conditions on Selected Properties of Biodiesel Produced from Palm-Based Waste Cooking Oils
}

\author{
Vladimir Plata ${ }^{1, *}$, Deyanira Ferreira-Beltrán ${ }^{2}$ and Paola Gauthier-Maradei ${ }^{2}$
}

1 Grupo de Investigación en Ciencias Básicas y Aplicadas, Departamento de Ciencias Básicas, Universidad Santo Tomás Seccional Bucaramanga, Bucaramanga 68001, Colombia

2 Grupo de Investigación en Tecnologías de Valorización de Residuos y Fuentes Agrícolas e Industriales para la Sustentabilidad Energética, Escuela de Ingeniería Química, Universidad Industrial de Santander, Bucaramanga 68001, Colombia; deyanira2188239@correo.uis.edu.co (D.F.-B.); mapaomar@uis.edu.co (P.G.-M.)

* Correspondence: vladimir.plata@ustabuca.edu.co; Tel.: +57-7-6985858

Citation: Plata, V.; Ferreira-Beltrán,

D.; Gauthier-Maradei, P. Effect of

Cooking Conditions on Selected

Properties of Biodiesel Produced from Palm-Based Waste Cooking Oils. Energies 2022, 15, 908. https:// doi.org/10.3390/en15030908

Academic Editors: Francesco Calise, Neven Duić, Maria da Graça Carvalho, Qiuwang Wang, Poul Alberg Østergaard and Attilio Converti

Received: 14 December 2021

Accepted: 18 January 2022

Published: 27 January 2022

Publisher's Note: MDPI stays neutral with regard to jurisdictional claims in published maps and institutional affiliations.

Copyright: (C) 2022 by the authors. Licensee MDPI, Basel, Switzerland. This article is an open access article distributed under the terms and conditions of the Creative Commons Attribution (CC BY) license (https:// creativecommons.org/licenses/by/ $4.0 /)$.

\begin{abstract}
Cooking conditions affect oil properties and consequently, the quality of the derived biodiesel. Nevertheless, little information regarding the impact of the cooking process on biodiesel properties is currently available, especially for palm biodiesel. Therefore, this study examined the effect of cooking temperature, time of use, and length of reuse, on selected properties of biodiesel produced from palm-based waste cooking oils (WCO). Several WCO collected from restaurants belonging to four categories, namely fried chicken restaurants, fast food restaurants, snack producers, and typical restaurants, were subjected to base-catalyzed transesterification. The biodiesel yield was calculated, and the produced biodiesel was characterized as to its kinematic viscosity, calorific value, and cetane number. As a result, palm-based WCO performed better than other WCO in terms of biodiesel yield regardless of the conditions that they experienced, achieving almost $95 \%$ in some cases. The yield decreased as the cooking temperature and length of reuse moved upward, whereas the kinematic viscosity was sensitive only to the length of reuse, rising with increasing reuse. Non-compliance with biodiesel standards and technical requirements was observed in a few cases. The calorific value did not significantly change unless the cooking conditions were severe. The cetane number dropped as use and reuse decreased, remaining better compared to petrodiesel $(70.2 \pm 3.2$ on average). Typical restaurants would generate the most suitable WCO to produce biodiesel, i.e., yield: $93.1 \pm 0.2 \%$; kinematic viscosity: $5.0 \pm 0.3 \mathrm{~mm}^{2} / \mathrm{s}$; calorific value: $39.9 \pm 0.1 \mathrm{MJ} / \mathrm{kg}$; density: $919 \pm 9 \mathrm{~kg} / \mathrm{m}^{3}$; and cetane number: 67.4 on average. This is consistent with the less severe cooking conditions employed at these restaurants.
\end{abstract}

Keywords: cooking conditions; frying oils; physical properties; transesterification; biodiesel yield

\section{Introduction}

In recent years, biodiesel has attracted global attention due to its potential for replacing conventional diesel fuel [1]. In addition, it offers desirable characteristics, such as being renewable, biodegradable, and non-toxic [2]. Biodiesel is produced mainly through a transesterification process, which involves the chemical reaction of lipid feedstock (containing mostly triglycerides) with short-chain alcohol to yield fatty acid alkyl esters (biodiesel) and glycerol as byproducts (Figure 1) [3]. A strong base catalyst, e.g., $\mathrm{NaOH}, \mathrm{KOH}, \mathrm{CH}_{3} \mathrm{ONa}$, and $\mathrm{CH}_{3} \mathrm{OK}$, improves the transesterification reaction rate [4]. Edible oils, including soybean, rapeseed, and palm oil, are the principal biodiesel feedstocks. However, the high cost of these oils represents the main barrier to the commercialization of biodiesel [5].

Using waste cooking oils (WCO) as a biodiesel feedstock not only causes a significant reduction in production costs but also eliminates competition within the food industry; it also offers an acceptable way of disposing of such waste [3]. Nevertheless, a drawback of producing biodiesel from frying oils is that this material contains several impurities that 
may lead to undesirable side reactions, such as saponification and hydrolysis, decreasing the biodiesel yield and affecting its quality [6]. Figure 2 depicts a simplified process diagram.<smiles>[R]C(=O)OCC(COC(=O)CC)OCCC</smiles>

Triglyceride<smiles>[R]C(=O)OCC(CO)OC([R])=O</smiles>

Diglyceride<smiles>[R]C(=O)OCC(O)CO</smiles>

Monoglyceride

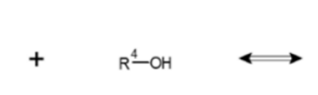

Alcohol

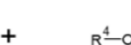

$\mathrm{R}^{4}-\mathrm{OH}$

Alcohol

$$
+\quad \mathrm{R}^{4}-\mathrm{OH}
$$

Alcohol<smiles>[R]C(=O)OCC(CO)OC([Z])=O</smiles>

Diglyceride<smiles>O=C(O)OCC(O)CO</smiles>

Monoglyceride

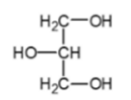

Glycerol<smiles>[R]OC([R])=O</smiles>

Alkyl ester<smiles>[R]OC([R])=O</smiles>

Alkyl ester<smiles>[R]C(=O)OCCOCCO</smiles>

Alkyl ester

Figure 1. Transesterification reaction scheme. $R^{1}, R^{2}$, and $R^{3}$ represent the triglyceride fatty acid chains. $\mathrm{R}^{4}$ represents the alcohol chain.

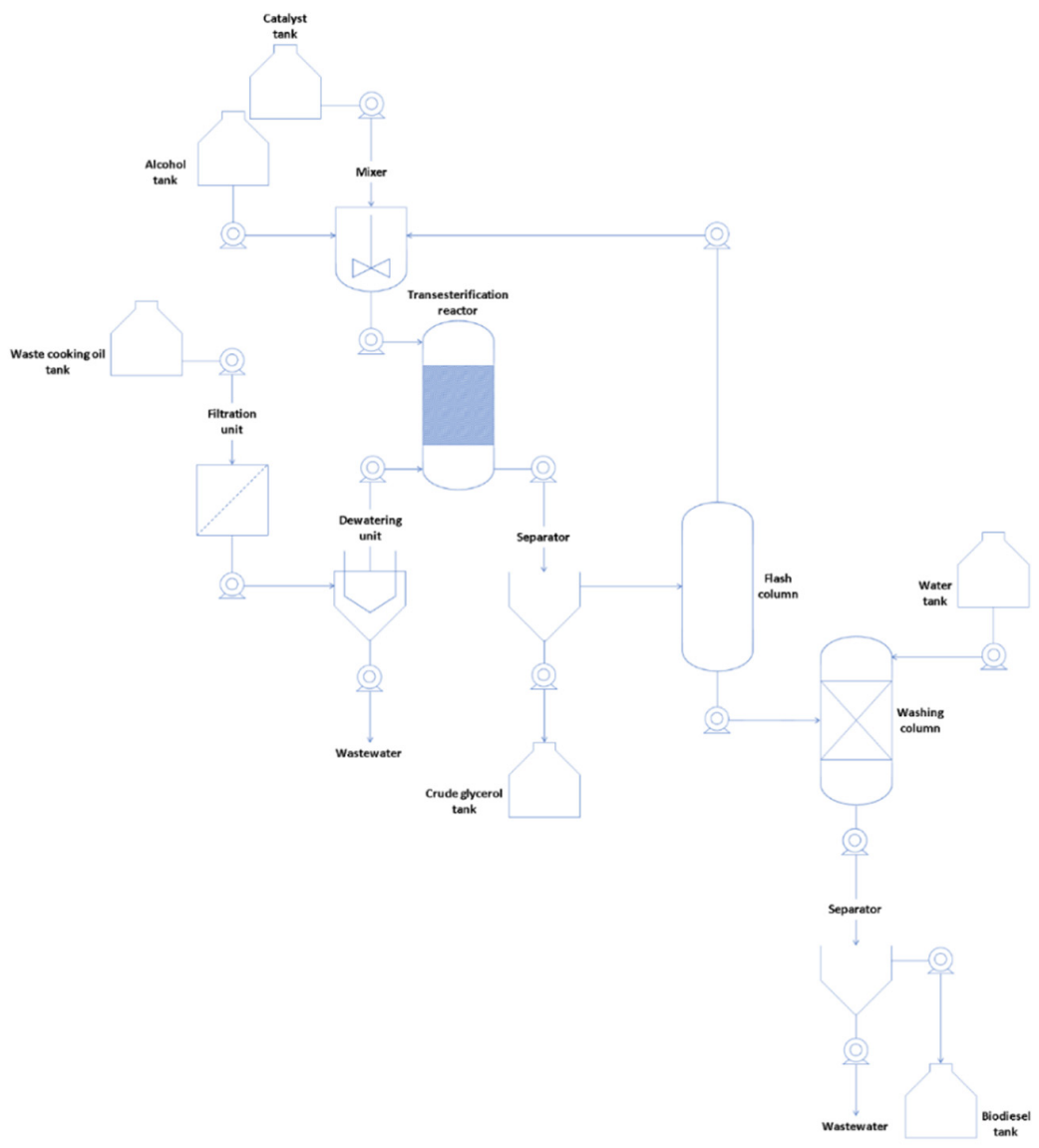

Figure 2. Simplified process diagram for waste cooking oil transesterification.

Conventionally, biodiesel production from WCO comprises a series of upstream and downstream steps involving separation processes, apart from the transesterification reaction [7]. First, suspended solids are removed by filtration, and moisture is eliminated by heating above $100{ }^{\circ} \mathrm{C}$. Then, triglycerides are converted into fatty acid alkyl esters 
upon reacting pretreated $\mathrm{WCO}$ and an alcoholic solution of the base catalyst. Afterward, the reaction products are separated, employing a gravity settler. Finally, the biodiesel is purified, utilizing a flash column for alcohol removal and a wash column to eliminate the catalyst and soap. Cooking conditions, namely the cooking temperature, time of use, and length of reuse, affect the oils properties, and consequently, the quality of biodiesel derived thereof [8]. Several studies have examined the changes in oils exposed to varying conditions [9]. However, little information regarding the impact of the cooking process on biodiesel properties is currently available to the best of our knowledge. So far, the effect of the cooking temperature and time on selected properties of biodiesel produced from canola-, sunflower-, and corn-based WCO has been evaluated [10]. Nevertheless, the impact of the length of reuse, which is a critical cooking condition [9], has not been investigated nor has the effect on biodiesel yield. Therefore, this study examined the effect of cooking conditions on the yield and selected properties of biodiesel produced from palm-based WCO. Since the variability in the WCO properties among restaurants may concern their use as a biodiesel feedstock [8], determining which type of restaurant would generate the most suitable WCO is a related objective.

\section{Materials and Methods}

\subsection{Materials}

WCO were collected from 8 restaurants in Bucaramanga, Colombia. The restaurants belonged to four categories: Fried chicken restaurants (FCR), fast food restaurants (FFR), snack producers (SP), and typical restaurants (TR). Data on the cooking conditions employed at each restaurant was obtained using a short survey completed by persons in charge of the restaurants.

\subsection{WCO Conditioning}

The WCO were conditioned by filtration through a cloth sieve (47-mm diameter) under vacuum for $10 \mathrm{~min}$ followed by centrifugation at $5800 \mathrm{rpm}$ for $20 \mathrm{~min}$ and filtration through Whatman No. 2 filter paper (47-mm diameter) under vacuum for $10 \mathrm{~min}$. The oils were then stored in dark bottles at $25^{\circ} \mathrm{C}$ under a dry nitrogen atmosphere.

\subsection{WCO Characterization}

The WCO were characterized as to their acid value, peroxide value, and viscosity at $40{ }^{\circ} \mathrm{C}$ following the AOAC 940.28 [11], AOAC 965.33 [12], and ASTM D2196 Standard Test Method [13], respectively. Each analysis was conducted in duplicate.

\subsection{Biodiesel Production and Characterization}

The WCO were transesterified using a sealed 1-L glass reactor equipped with a methanol/KOH mixture container, a reflux condenser, a heating bath, a temperature controller, and a magnetic stirrer (Figure 3). First, $200 \mathrm{~g}$ of oil were placed in the reactor, stirred at $400 \mathrm{rpm}$, and heated at $60{ }^{\circ} \mathrm{C}$. Then, a mixture of methanol $(44 \mathrm{~g})$ and $\mathrm{KOH}$ $(2 \mathrm{~g})$ was added to the oil, and the resulting mixture reacted for $60 \mathrm{~min}$. As a result, the methanol/oil molar ratio was 6:1, and the $\mathrm{KOH} /$ oil mass ratio was 0.01 . Afterward, the reaction mixture was transferred to a separatory funnel and left to settle for $12 \mathrm{~h}$. Then, the glycerol layer was removed, and the biodiesel layer was washed several times with distilled water at $50{ }^{\circ} \mathrm{C}$ (water/biodiesel 1:1 volume ratio) until reaching a neutral $\mathrm{pH}$. After washing, the biodiesel was heated at $110^{\circ} \mathrm{C}$ for $20 \mathrm{~min}$ to remove excess methanol and water and stored in dark bottles at $25^{\circ} \mathrm{C}$ under a dry nitrogen atmosphere. 


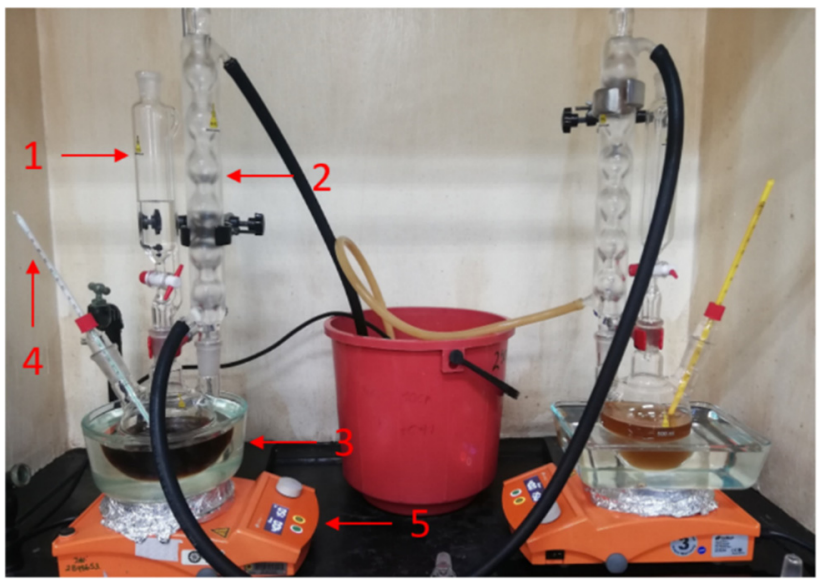

Figure 3. Photograph view of the reactor utilized for biodiesel production, including (1) a methanol/KOH mixture container, (2) a reflux condenser, (3) a heating bath, (4) a temperature controller, and (5) a magnetic stirrer.

The biodiesel yield was calculated according to Equation (1):

$$
\text { Biodiesel yield }(\%)=\frac{\text { Mass of biodiesel produced }}{\text { Initial mass of WCO }} \times 100 \text {. }
$$

The biodiesel fatty acid profile was determined by Laboratorio de Cromatografía y Espectrometría de Masas (CROM-MASS) at Universidad Industrial de Santander (Bucaramanga, Colombia) in accordance with the ISO 5508 and 5509 Standards [14,15]. Viscosity at $40^{\circ} \mathrm{C}$ was determined following the ASTM D2196 Standard Test Method [13]. Calorific value was measured using a PARR 6200 calorimeter bomb. Density at $40{ }^{\circ} \mathrm{C}$ was determined using a calibrated pycnometer. The cetane number was predicted using Equation (2):

$$
\text { Cetane number }=\sum \% M E \cdot C N_{M E}
$$

where $\% \mathrm{ME}$ and $\mathrm{CN}_{\mathrm{ME}}$ are the mass $\%$ and cetane number of each methyl esters, respectively [16]. Each analysis was conducted in duplicate. To better understand the cooking conditions' impact on the cetane number, the unsaturation degree (UD) was calculated using Equation (3) and the biodiesel fatty acid profile:

$$
U D=(1 \cdot \% M U+2 \cdot \% D U+3 \cdot \% T U) / 100 .
$$

where $\% \mathrm{MU}$ is the total mass $\%$ of monounsaturated fatty acid, $\% \mathrm{DU}$ is the total mass $\%$ of diunsaturated fatty acid, and \%TU is the total mass $\%$ of triunsaturated fatty acid [16].

\subsection{Statistical Analysis}

Data were analyzed by ANOVA followed by the Fisher's Least Significant Difference (LSD) test for multiple comparisons using Statgraphics Centurion software (free trial version, StatPoint Technologies, Inc., Warrenton, VA, USA). A $p$-value of $<0.05$ was considered statistically significant.

\section{Results and Discussion}

\subsection{Fatty Acid Composition}

Palmitic acid (C16:0) and oleic acid (C18:1) were the primary fatty acids of the WCO (Table 1). Stearic acid (C18:0), linoleic acid (C18:2), and linolenic acid (C18:3) were also present, although at lower levels. This is characteristic of palm-based oils [17]. Some oils, especially TR2, seemed to have a comparatively low palmitic acid content. However, the fatty acids profile corresponded to saturated oils ( $41.44 \%$ of saturates on average). 
Table 1. Fatty acid composition of representative palm-based waste cooking oils (WCO). Relative standard deviation was within $2 \%$ of average $(n=2)$. FCR denotes fried chicken restaurants; FFR denotes fast food restaurants; SP denotes snacks producers; and TR denotes traditional restaurants.

\begin{tabular}{|c|c|c|c|c|c|c|c|c|c|}
\hline WCO & C16:0 & C16:1 & C18:0 & C18:1 & C18:2 & C18:3 & C20:0 & $\sum$ SFA $^{\mathbf{a}}$ & $\sum \mathbf{U F A}^{\mathbf{b}}$ \\
\hline FCR1 & 40.36 & 3.92 & 2.78 & 51.68 & 0.65 & 0.31 & 0.30 & 43.44 & 56.56 \\
\hline FCR2 & 34.62 & 2.30 & 1.79 & 60.31 & 0.50 & 0.22 & 0.26 & 36.67 & 63.33 \\
\hline FFR1 & 43.47 & 1.15 & 2.55 & 51.53 & 0.63 & 0.22 & 0.44 & 46.47 & 53.53 \\
\hline FFR2 & 33.98 & 0.98 & 2.44 & 59.87 & 2.08 & 0.22 & 0.42 & 36.84 & 63.16 \\
\hline SP1 & 48.47 & 1.33 & 2.49 & 46.69 & 0.14 & 0.47 & 0.40 & 51.37 & 48.63 \\
\hline SP2 & 50.97 & 1.82 & 2.60 & 43.02 & 0.20 & 0.92 & 0.46 & 54.04 & 45.96 \\
\hline TR1 & 42.34 & 2.40 & 3.03 & 50.87 & 0.64 & 0.33 & 0.39 & 45.76 & 54.24 \\
\hline TR2 & 13.93 & 0.52 & 2.57 & 78.43 & 3.75 & 0.40 & 0.41 & 16.91 & 83.09 \\
\hline Average & & & & & & & & 41.44 & 58.56 \\
\hline
\end{tabular}

${ }^{\mathrm{a}} \sum \mathrm{SFA}=\mathrm{C} 16: 0+\mathrm{C} 18: 0+\mathrm{C} 20: 0 ;{ }^{\mathrm{b}} \sum \mathrm{UFA}=\mathrm{C} 16: 1+\mathrm{C} 18: 1+\mathrm{C} 18: 2+\mathrm{C} 18: 3$.

\subsection{Biodiesel Yield}

According to ANOVA and LSD multiple range test results, biodiesel yield means were grouped into four homogeneous groups identified by "a" to " $\mathrm{d}$ " (Figure 4), each of which was significantly different from the rest at a 95\% level of confidence ( $p$-value $<0.0001)$. On the other hand, no significant differences existed among TR1, TR2, FCR2, FFR2, and FFR1. Hence, FFR1 was identified by combining "a" and "b."

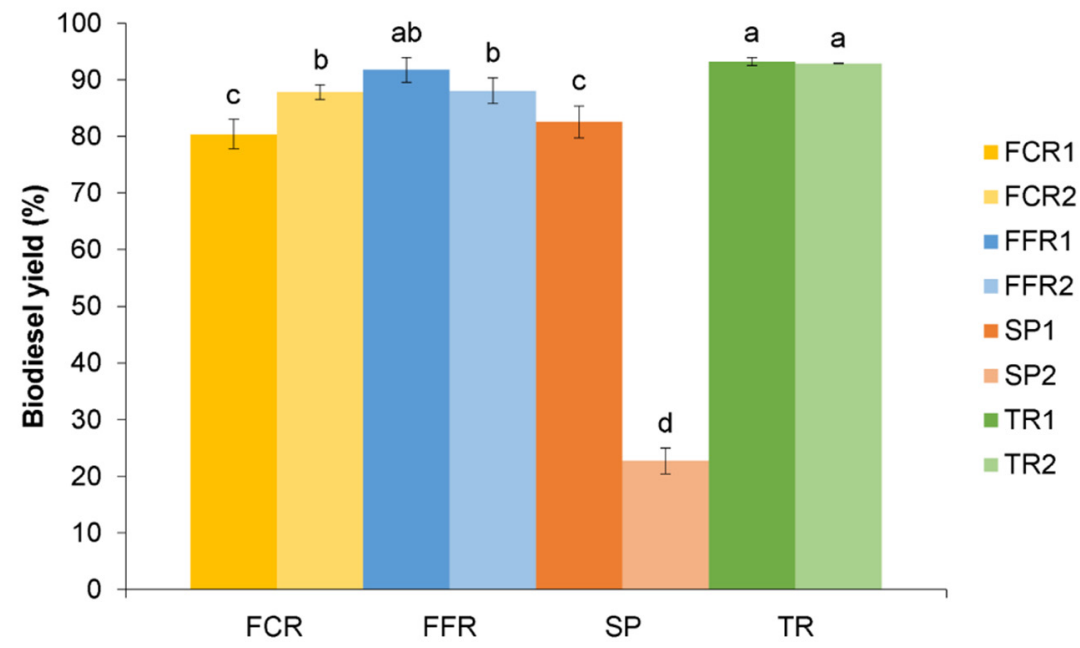

Figure 4. Biodiesel yield provided by representative palm-based waste cooking oils. Means with different letters are significantly different by LSD (Least Significant Difference) multiple range test ( $p$-value $<0.05)$. Error bars show standard deviation. For details on abbreviations, refer to Table 1.

As shown in Figure 4, TR1 and TR2 (group "a") provided the highest biodiesel yield, followed by FCR2 and FFR2 (group "b"), FCR1 and SP1 (group "c"), and SP2 (group "d"). Except for groups " $c$ " and "d," the yield was $>88 \%$, and for group "a," it was close to $95 \%$ (Figure 4 ). These results overcome those reported for other WCO. For example, Wyse-Mason and Beckles transesterified several soybean-based WCO using a base catalyst and achieved a yield of $82 \%$ at best [7].

The low biodiesel yield given by FCR1 and SP2 is consistent with their high acid value (Table 2). During base-catalyzed transesterification, the free fatty acids in oils react with the catalyst to form soaps. As a consequence, the oil conversion into biodiesel decreases [18]. Nevertheless, the yield provided by FCR1 and SP2 confirmed that palm-based WCO performed better as biodiesel feedstock. Wyse-Mason and Beckles attained $<6 \%$ with soybean-based WCO subjected to similar cooking conditions [7]. 
Table 2. Selected properties of representative palm-based waste cooking oils. Relative standard deviation was within $3 \%$ of the average. For details on abbreviations, refer to Table 1.

\begin{tabular}{lccc}
\hline WCO & $\begin{array}{c}\text { Acid Value } \\
\mathbf{m g} \mathbf{~ K O H} / \mathbf{g}\end{array}$ & $\begin{array}{c}\text { Peroxide Value } \\
\text { meq } \mathbf{~}_{\mathbf{2}} / \mathbf{k g}\end{array}$ & $\begin{array}{c}\text { Dynamic Viscosity } \\
\mathbf{c P}\end{array}$ \\
\hline FCR1 & 5.17 & 6.62 & 42.4 \\
FCR2 & 2.71 & 2.19 & 48.8 \\
FFR1 & 1.31 & 2.84 & 45.8 \\
FFR2 & 3.14 & 5.91 & 47.7 \\
SP1 & 1.26 & 12.47 & 48.3 \\
SP2 & 8.79 & 6.53 & 72.5 \\
TR1 & 1.04 & 6.53 & 46.7 \\
TR2 & 1.87 & 2.04 & 34.1 \\
\hline
\end{tabular}

The high acid value of FCR1 and SP2 is attributable to the severe conditions they experienced (Table 3). FCR1 was exposed to $>300{ }^{\circ} \mathrm{C}$, whereas SP2 was subjected to $>13 \mathrm{~h}$ of daily use. During cooking, the moisture in oils and food hydrolyzes the ester bond of triglycerides, and prolonged the contact of oils with the aqueous phase as high temperatures increases hydrolysis and the free fatty acids content [9]. Thus, FCR1 and SP2 gave poor biodiesel yields.

Table 3. Cooking conditions that representative palm-based waste cooking oils experienced. For details on abbreviations, refer to Table 1.

\begin{tabular}{lllll}
\hline WCO & $\begin{array}{l}\text { Cooking } \\
\text { Temperature } \\
\left({ }^{\circ} \mathbf{C}\right)\end{array}$ & $\begin{array}{l}\text { Time of Use } \\
\text { (h/Day) }\end{array}$ & $\begin{array}{l}\text { Length of Reuse } \\
\text { (Day) }\end{array}$ & Food Cooked \\
\hline FCR1 & $>300$ & $3-5$ & $3-7$ & $\begin{array}{l}\text { Chicken, fries, } \\
\text { plantain slices }\end{array}$ \\
FCR2 & $>300$ & $8-13$ & $1-3$ & $\begin{array}{l}\text { Chicken, fries } \\
\text { FFR1 }\end{array}$ \\
FFR2 & $250-300$ & $8-13$ & $3-7$ & Fries \\
SP1 & $150-250$ & $5-8$ & $3-7$ & Fries, sausages \\
SP2 & $150-200$ & $5-8$ & $1-3$ & Potato chips \\
TR1 & $<150$ & $>13$ & $3-7$ & Empanadas \\
TR2 & $<150$ & $3-5$ & $1-3$ & Meat, fries \\
& & $8-13$ & $1-3$ & $\begin{array}{l}\text { Meat, fries, } \\
\text { plantain slices }\end{array}$ \\
\hline
\end{tabular}

FCR2 was also heated to above $300{ }^{\circ} \mathrm{C}$. However, it provided a superior yield than FCR1 (8.5\% higher), even though FCR2 was used longer. This is probably due to the difference in the length of reuse. FCR1 was reused twice as long (3-7 versus 1-3 days of consecutive reuse), raising the number of fryings. As frying moves upward, the oils become more degraded [9]. Intermittent heating results in higher deterioration because oxygen solubility increases as the oils cool down [19]. This is consistent with the higher peroxide value of FCR1. Consequently, the oil conversion appears to drop with rising reuse.

TR2 was exposed to lower temperatures than FCR2 under identical conditions of use and reuse and gave a better biodiesel yield (5.8\% higher). In contrast, TR1 and TR2 showed a non-statistically significant difference, even though TR2 was subjected to more prolonged use over the same 3-day period at similar temperatures. This indicates that the cooking temperature and length of reuse have a significant effect on oil conversion, whereas the time of use does not unless it overcomes $13 \mathrm{~h}$ /day, as discussed above for SP2. On the other hand, the yield may not significantly vary when the cooking temperature rises slightly and, simultaneously, the length of reuse remains constant, as evidenced by FFR1 and FFR2.

FFR1 was heated to higher temperatures and used as long as SP2 over the same 7-day period. Nevertheless, it provided a marked different biodiesel yield ( $75.2 \%$ higher). This may seem to contradict the previous discussion, but it suggests that the type of food cooked is another factor that affects the oil conversion. As shown in Table 3, FFR1 was utilized for 
cooking fries, whereas SP2 was employed to prepare empanadas. An empanada is a fried snack consisting of wheat flour pastry and filling. Both fries and wheat flour are composed of starch [20,21], which promotes oxidation [9]. However, fries have a lower starch content, causing FFR1 to be less degraded (2.21 vs. $6.53 \mathrm{meq} \mathrm{O}_{2} / \mathrm{kg}$ observed for SP2).

\subsection{Viscosity}

According to ANOVA and LSD multiple range test results, kinematic viscosity means were grouped into three homogeneous groups identified by " $a$ " to " $c$ " (Figure 5), each of which was significantly different from the rest at a 95\% level of confidence ( $p$-value $<0.0001)$. On the other hand, no significant differences existed among FCR1, FFR1, FCR2, TR2, FFR2, SP1, and TR1. Hence, FFR2, SP1, and TR1 were identified by combining " $b$ " and " $c$ ".

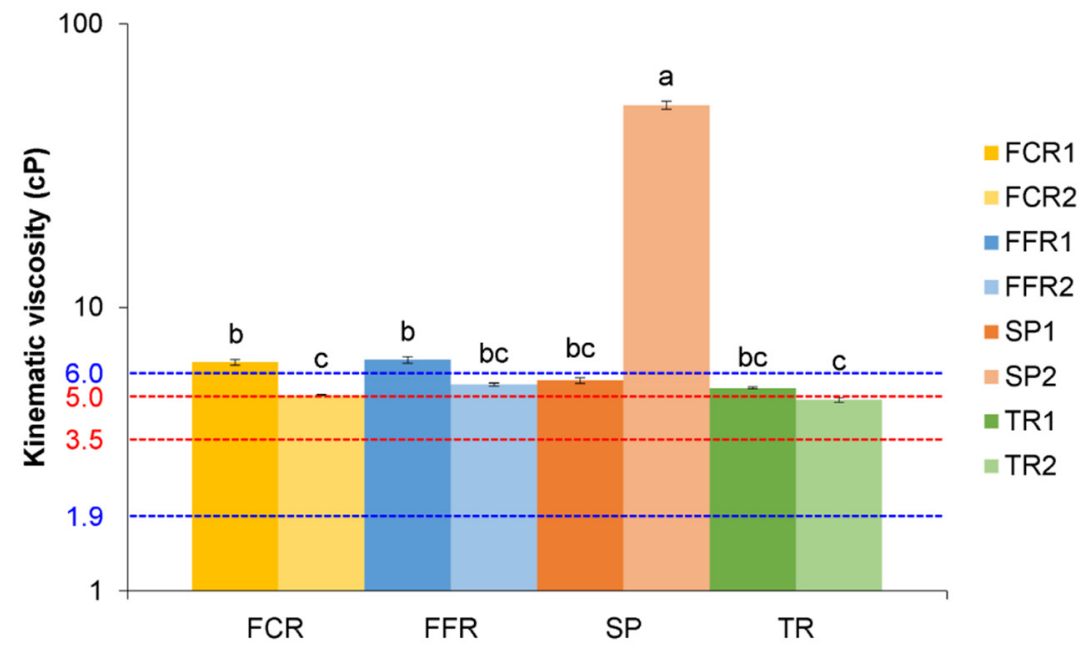

Figure 5. Kinematic viscosity of biodiesel derived from representative palm-based waste cooking oils. The blue and red dotted lines indicate the ASTM D6751 and EN 14214 limits for this property, respectively. Means having different letters are significantly different by LSD multiple range test ( $p$-value $<0.05)$. Error bars show standard deviation. For details on abbreviations, refer to Table 1.

As shown in Figure 5, SP2 (group "a") provided the highest kinematic viscosity, followed by FCR1 and FFR1 (group " $b$ "), and FCR2, TR2 (group " $c$ "). With the exception of groups " $a$ " and " $b$ ", the viscosity was within the range required by the American biodiesel standard ASTM D6751 (1.9-6.0 mm²/s) [22]. Besides, group " $\mathrm{c}$ " met the stricter EN 14214 specifications (3.5-5.0 $\mathrm{mm}^{2} / \mathrm{s}$ ) [23] (Figure 5). This is desirable in biodiesel, as high viscosities demand more energy from the pump to move the fuel through the filter and lines, leading to wear on the pump [24].

No significant differences existed between FCR2 and TR2, even though FCR2 experienced higher temperatures. Similarly, TR1 did not statistically differ from TR2, even though TR2 was subjected to more extended use. By contrast, FCR1 was reused longer than FCR2 and yielded biodiesel with a higher viscosity. This evidences that biodiesel viscosity is sensitive only to the length of reuse, moving upward as reuse increases. Prolonged reuse promotes the formation of polymers of triglycerides that raise the oil viscosity, and therefore, the biodiesel viscosity [9].

\subsection{Calorific Value}

According to ANOVA and LSD multiple range test results, calorific value means were grouped into two homogeneous groups identified by " $a$ " and " $b$ " (Figure 6), each of which was significantly different from the rest at a 95\% level of confidence $(p$-value $<0.0001)$. As shown in Figure 6, except for SP2 (group " $b$ "), the WCO yielded biodiesel with a calorific value superior to that reported for other WCO (39.1 MJ/kg [25], $38.5 \mathrm{MJ} / \mathrm{kg}$ [26], $37.2 \mathrm{MJ} / \mathrm{kg}$ [27], 35.7 MJ/kg [3]) (Figure 6). Even so, the calorific value remained lower 
compared to petrodiesel (41.2 MJ $/ \mathrm{kg}$ ) [3]. Nevertheless, the higher density of the produced biodiesel (Figure 7) compensates for its reduced energy content, so the amount of fuel injected into the combustion chamber may not require adjustment to achieve similar power outputs to petrodiesel [3]. Furthermore, all but one calorific value did not significantly change. This indicates that the cooking process does not affect the calorific value unless the conditions are severe.

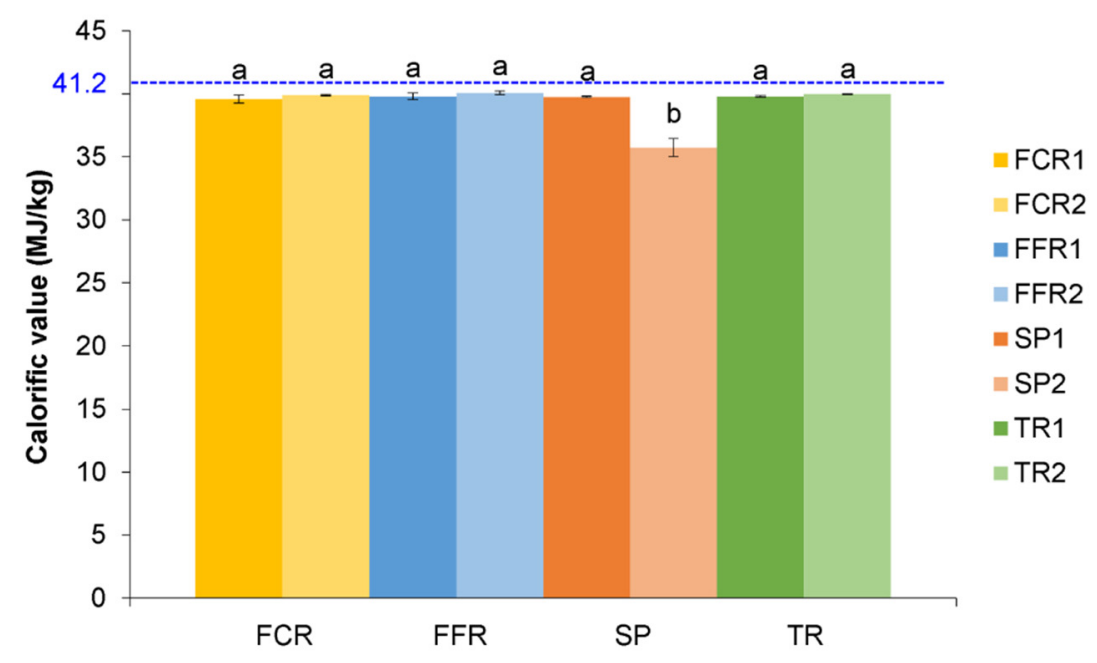

Figure 6. Calorific value of biodiesel derived from representative palm-based waste cooking oils. The blue dotted line indicates the $41.2 \mathrm{MJ} / \mathrm{kg}$ value reported for petrodiesel [3]. Means having different letters are significantly different by LSD multiple range test ( $p$-value $<0.05)$. Error bars show standard deviation. For details on abbreviations, refer to Table 1.

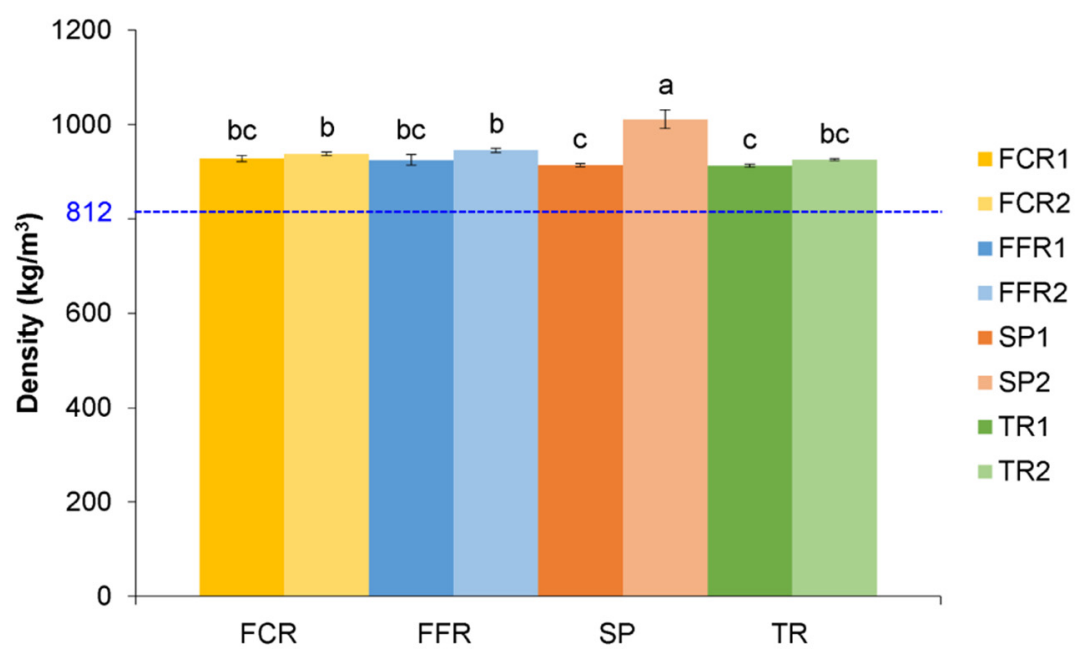

Figure 7. Density of biodiesel derived from representative palm-based waste cooking oils. The blue dotted line indicates the $812 \mathrm{~kg} / \mathrm{m}^{3}$ value reported for petrodiesel [28]. Means having different letters are significantly different by LSD multiple range test ( $p$-value $<0.05$ ). Error bars show standard deviation. For details on abbreviations, refer to Table 1.

\subsection{Cetane Number}

The cetane number of petrodiesel is generally estimated using the cetane index [29]. In contrast, the cetane number of biodiesel is predicted using correlations based on its fatty acid profile [30]. In addition, biodiesel's ignition behavior is typically better compared to petrodiesel [31]. Accordingly, the WCO all yielded biodiesel with a superior cetane number (70.2 \pm 3.2 on average versus 45 observed for petrodiesel [32]) (Figure 8). 


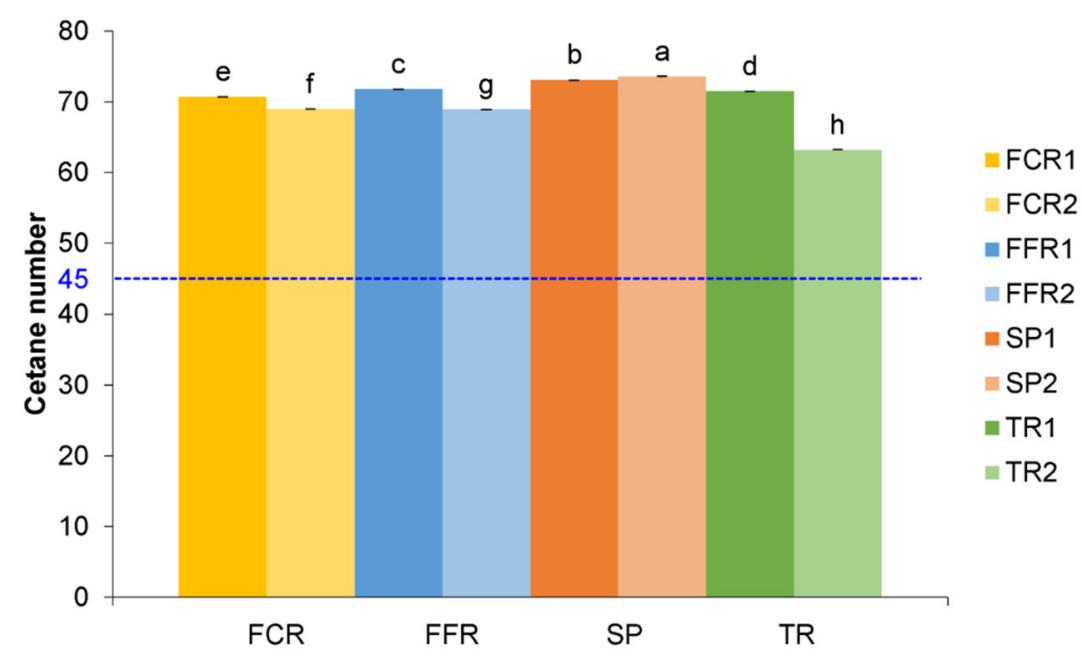

Figure 8. Cetane number of biodiesel derived from representative palm-based waste cooking oils. The blue dotted line indicates a value of 45 reported for petrodiesel [32]. Means having different letters are significantly different by LSD multiple range test ( $p$-value $<0.05)$. Error bars show standard deviation. For details on abbreviations, refer to Table 1.

According to ANOVA and LSD multiple range test results, cetane number means were grouped into eight homogeneous groups identified by "a" to " $h$ " (Figure 8), each of which was significantly different from the rest at a $95 \%$ level of confidence ( $p$-value $<0.0001)$. In agreement with the literature [16], the cetane number moved upward as UD decreased (Figure 9), the highest cetane number corresponding to SP2. This is attributable to the severe conditions it experienced. During cooking, hydration of unsaturated fatty acids may occur [33], dropping the UD value. SP2 was subjected to extended use and reuse and attained the lowest UD. In consequence, the cetane number increases with rising use and reuse.

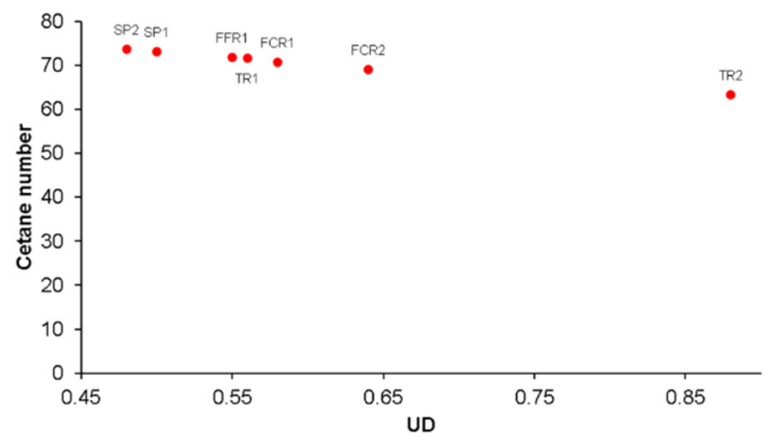

Figure 9. Relationship between the cetane number and unsaturation degree of biodiesel derived from representative palm-based waste cooking oils. For details on abbreviations, refer to Table 1.

\subsection{Effect of Type of Restaurant}

The properties examined demonstrated the quality of most of the produced biodiesel. However, because of the interest in determining which type of restaurant would generate the most suitable WCO to produce biodiesel, the results obtained for fried chicken restaurants, fast food restaurants, and traditional restaurants were analyzed by categories. Snacks producers were not considered because of the high variance of their results (Table 4). 
Table 4. Average biodiesel yield, kinematic viscosity, calorific value, density, and cetane number of biodiesel derived from representative palm-based waste cooking oils. For details on abbreviations, refer to Table 1.

\begin{tabular}{lcccc}
\hline Property & FCR & FFR & SP & TR \\
\hline Biodiesel yield $(\%)$ & $84.1 \pm 5.3^{\mathrm{a}}$ & $89.9 \pm 2.6$ & $52.6 \pm 42.3$ & $93.1 \pm 0.2$ \\
Kinematic viscosity & $5.7 \pm 1.1$ & $5.9 \pm 0.8$ & $28.6 \pm 32.6$ & $5.0 \pm 0.3$ \\
$\left(\mathrm{~mm}^{2} / \mathrm{s}\right)$ & $39.7 \pm 0.2$ & $39.9 \pm 0.2$ & $37.7 \pm 2.9$ & $39.9 \pm 0.1$ \\
Calorific value $(\mathrm{MJ} / \mathrm{kg})$ & $932 \pm 7$ & $935 \pm 14$ & $962 \pm 69$ & $919 \pm 9$ \\
Density $\left(\mathrm{kg} / \mathrm{m}^{3}\right)$ & 69.9 & 70.4 & 73.3 & 67.4 \\
Cetane number & &
\end{tabular}

a Values are the mean \pm standard deviation, except for cetane number, whose standard deviation was between 0.0001 and 0.0126

The type of restaurant had a significant impact only on the biodiesel yield ( $p$-value $=0.0087$ ). Kinematic viscosity, calorific value, density, and cetane number all showed no significant differences across the restaurant types ( $p$-value $=0.1464,0.4196,0.1008$, and 0.3634 , respectively). This suggests that the yield is more sensitive to cooking conditions than the other properties. Moreover, the average biodiesel yield observed for typical restaurants was close to that expected for virgin oils [34], evidencing that these restaurants would generate the most suitable WCO to produce biodiesel. This is probably due to the less severe cooking conditions employed at these restaurants.

\section{Conclusions}

Fisher's Least Significant Difference test for multiple comparisons successfully examined the effect of cooking conditions on selected properties of biodiesel produced from palm-based WCO. These oils performed better than other WCO in terms of biodiesel yield regardless of the conditions that they experienced. The yield decreased as the cooking temperature and length of reuse moved upward, whereas the kinematic viscosity was sensitive only to the length of reuse, rising with increasing reuse. Non-compliance with biodiesel standards and technical requirements was observed in some cases. The calorific value did not significantly change unless the cooking conditions were severe. The cetane number dropped as use and reuse decreased, remaining better compared to petrodiesel nonetheless. Typical restaurants would generate the most suitable WCO to produce biodiesel. This is consistent with the less severe cooking conditions employed at these restaurants.

Author Contributions: V.P.: Conceptualization, formal analysis, writing-Original draft preparation, funding acquisition, supervision. D.F.-B.: Methodology, investigation, data curation, validation, formal analysis. P.G.-M.: Formal analysis, writing-Review and editing, supervision. All authors have read and agreed to the published version of the manuscript.

Funding: The authors gratefully acknowledge the support of the Universidad Santo Tomás Seccional Bucaramanga (Project No. GIDPTOCBASICP22017) and the Ministerio de Ciencia Tecnología e Innovación (MINCIENCIAS) through the "Formación de Capital Humano de Alto Nivel para el Departamento de Santander 2016, modalidad de Maestría Nacional" program.

Institutional Review Board Statement: Not applicable.

Informed Consent Statement: Not applicable.

Data Availability Statement: All data generated or analyzed in this study are included in the article.

Conflicts of Interest: The authors declare no conflict of interest.

\section{References}

1. Plata, V.; Rojas, O.; Gauthier-Maradei, P. Improvement of palm oil biodiesel filterability by treatment with reactivated. Fuel 2020, 260, 116198. [CrossRef]

2. Plata, V.; Gauthier-Maradei, P.; Kafarov, V. Influence of minor components on precipitate formation and filterability of palm oil biodiesel. Fuel 2015, 144, 130-136. [CrossRef] 
3. Al-Hamamre, Z.; Yamin, J. Parametric study of the alkali catalyzed transesterification of waste frying oil for biodiesel production. Energy Convers. Manag. 2014, 79, 246-254. [CrossRef]

4. Sharma, Y.C.; Singh, B. Development of biodiesel: Current scenario. Renew. Sust. Energy Rev. 2009, 13, 1646-1651. [CrossRef]

5. Fonseca, J.M.; Teleken, J.G.; Almeida, V.C.; Da Silva, C. Biodiesel from waste frying oils: Methods of production and purification. Energy Convers. Manag. 2019, 184, 205-218. [CrossRef]

6. Yaakob, Z.; Mohammad, M.; Alherbawi, M.; Alam, Z.; Sopian, K. Overview of the production of biodiesel from waste cooking oil. Renew. Sust. Energy Rev. 2013, 18, 184-193. [CrossRef]

7. Zhang, Y.; Dubé, M.A.; McLean, D.D.; Kates, M. Biodiesel production from waste cooking oil: 1. Process design and technological assessment. Bioresour. Technol. 2003, 89, 1-16. [CrossRef]

8. Wyse-Mason, R.R.; Beckles, D.M. An investigation of restaurant waste oil characteristics for biodiesel production in Trinidad and Tobago. Energy Sustain. Dev. 2012, 16, 515-519. [CrossRef]

9. Choe, E.; Min, D.B. Chemistry of deep-fat frying oils. J. Food Sci. 2007, 72, R77-R86. [CrossRef]

10. Dogan, T.H. The testing of the effects of cooking conditions on the quality of biodiesel produced from waste cooking oils. Renew. Energy 2016, 94, 466-473. [CrossRef]

11. AOAC. Fatty acids (free) in crude and refined oils. In Official Methods of Analysis, 21st ed.; Latimer, G.W., Ed.; AOAC International: Rockville, MD, USA, 2019.

12. AOAC. Peroxide Value. In Official Methods of Analysis, 21st ed.; Latimer, G.W., Ed.; AOAC International: Rockville, MD, USA, 2019.

13. ASTM. Standard test methods for rheological properties of non-newtonian materials by rotational viscometer. In Annual Book of ASTM Standards; ASTM International: West Conshohocken, PA, USA, 2012.

14. ISO. Animal and Vegetable Fats and Oils-Analysis by Gas Chromatography of Methyl Esters of Fatty Acids; ISO Publications: Geneva, Switzerland, 1990.

15. ISO. Animal and Vegetable Fats and Oils_Preparation of Methyl Esters of Fatty Acids; ISO Publications: Geneva, Switzerland, 2000.

16. Carmona-Cabello, M.; Leiva-Candia, D.; Castro-Cantarero, J.L.; Pinzi, S.; Dorado, M.P. Valorization of food waste from restaurants by transesterification of the lipid fraction. Fuel 2018, 215, 492-498. [CrossRef]

17. Mba, O.I.; Dumont, M.J.; Ngadi, M. Palm oil: Processing, characterization and utilization in the food industry: A review. Food Biosci. 2015, 10, 26-41. [CrossRef]

18. Mendoza, L.; Plata, V.; Gauthier-Maradei, P. Effect of minor components on chemical composition, thermal behavior, and morphology of biodiesel precipitate. Fuel 2018, 228, 323-331. [CrossRef]

19. Clark, W.L.; Serbia, G.W. Safety aspects of frying fats and oils. Food Technol. 1991, 45, 84-89.

20. Abbasi, K.S.; Qayyum, A.; Mehmood, A.; Mahmood, T.; Khan, S.U.; Liaquat, M.; Sohail, A.; Ahmad, A. Analysis of selective potato varieties and their functional assessment. Food Sci. Technol. 2019, 39, 308-314. [CrossRef]

21. Andersson, R.; Westerlund, E.; Tilly, A.C.; Aman, P. Natural variations in the chemical composition of white flour. J. Cereal Sci. 1993, 17, 183-189. [CrossRef]

22. ASTM. Standard specification for biodiesel fuel (B100) blend stock for distillate fuels. In Annual Book of ASTM Standards; ASTM International: West Conshohocken, PA, USA, 2012.

23. CEN. Liquid Petroleum Products-Fatty Acid Methyl Esters (FAME) for Use in Diesel Engines and Heating Applications-Requirements and Test Methods; CEN Publications: Brussels, Belgium, 2012.

24. Tesfa, B.; Mishra, R.; Gu, F.; Powles, N. Prediction models for density and viscosity of biodiesel and their effects on fuel supply system in CI engines. Renew. Energy 2010, 35, 2752-2760. [CrossRef]

25. Encinar, J.M.; Gonzalez, J.F.; Rodriguez-Reinares, A. Biodiesel from used frying oil. Variables affecting the yields and characteristics of the biodiesel. Ind. Eng. Chem. Res. 2005, 44, 5491-5499. [CrossRef]

26. Shalaby, E.A.; El Gendy, N.S. Two steps alkaline transesterification of waste cooking oil and quality assessment of the produced biodiesel. Int. J. Chem. Biochem. Sci. 2012, 1, 30-35.

27. Sahar, S.S.; Iqbal, J.; Ullah, I.; Bhatti, H.N.; Nouren, S.; Nisar, J.; Iqbal, M. Biodiesel production from waste cooking oil: An efficient technique to convert waste into biodiesel. Sustain. Cities Soc. 2018, 41, 220-226. [CrossRef]

28. Ivaniš, G.R.; Radovic, I.R.; Veljkovic, V.B.; Kijevcanin, M.L. Thermodynamic properties of biodiesel and petro-diesel blends at high pressures and temperatures. Experimental and modeling. Fuel 2016, 184, 277-288. [CrossRef]

29. Lapuerta, M.; Rodríguez-Fernández, J.; Armas, O. Correlation for the estimation of the density of fatty acid esters fuels and its implications. A proposed biodiesel cetane index. Chem. Phys. Lipids 2010, 163, 720-727. [CrossRef] [PubMed]

30. Knothe, G. A comprehensive evaluation of the cetane numbers of fatty acid methyl esters. Fuel 2014, 119, 6-13. [CrossRef]

31. Pinzi, S.; Garcia, I.L.; Lopez-Gimenez, F.J.; Luque de Castro, M.D.; Dorado, G.; Dorado, M.P. The ideal vegetable oil-based biodiesel composition: A review of social, economical and technical implications. Energy Fuels 2009, 23, 2325-2341. [CrossRef]

32. Schumacher, L.G.; Van Gerpen, J.; Adams, B. Biodiesel fuels. In Encyclopedia of Energy, 1st ed.; Cleveland, C.J., Ed.; Elsevier: Boston, MA, USA, 2004; Volume 1, pp. 151-162.

33. Knothe, G.; Steidley, K.R. A comparison of used cooking oils: A very heterogeneous feedstock for biodiesel. Bioresour. Technol. 2009, 100, 5796-5801. [CrossRef] [PubMed]

34. Shahbazi, M.R.; Khoshandam, B.; Nasiri, M.; Ghazvini, M. Biodiesel production via alkali-catalyzed transesterification of Malaysian RBD palm oil—Characterization, kinetics model. J. Taiwan Inst. Chem. Eng. 2012, 43, 504-510. [CrossRef] 